\title{
Sustainable Public Transportation System for Emerging Metropolitan Cite
}

\author{
Pratik R. Borkar, S. D. Ghodmare \\ ${ }^{I}$ PG Student, Civil Engineering Department, G. H. Raisoni College of Engineering, Nagpur \\ ${ }^{2}$ Assistant Professsor, Civil Engineering Department, G. H. Raisoni College of Engineering, Nagpur
}

\begin{abstract}
Nowadays, the number of the vehicles has gotten more and more than before, especially the private cars and two wheelers with the development of the economics in India. The urbanized course is also more and more quick in the big city automobile holds assumes the geometric series to grow but the transportation infrastructure rate of rise is lower by far than the vehicles actually the rate of rise, thus our country metropolitans are facing the huge traffic pressure. Public this also affected the urban economy increase in some kind of degree further to develop and the promotion of the people lives level. It also brings traffic jam, the accident, the energy waste and the environmental pollution causes the transportation to become restriction bottleneck in the economic development. The effective method of solving the city municipal transportation problem is to develop the public transit vigorously, especially to establish bus rapid transit system in the big city.
\end{abstract}

Keywords: transport planning; bus rapid transit system; entropy proportion means; sustainable development

\section{Introduction}

Sustainable development refers to a mode of human development in which resource use aims to meet human needs while ensuring the sustainability of natural systems and the environment, so that these needs can be met not only in the present, but also for generations to come. The term 'sustainable development' was used by the Brundtland Commission, which coined what has become the most often-quoted definition of sustainable development: "development that meets the needs of the present without compromising the ability of future generations to meet their own needs

Some cities in the world, especially those in developing countries, have adopted bus ways and bus lanes as cheap and feasible methods to alleviate the problems associated with high traffic demand and congestion. Rapid rail transit has proven to be unfeasible in most developing countries, requiring huge capital investments, sophisticated technology and technical expertise for its proper operation and maintenance of a level not likely to be found in most third world countries.

In developing countries, high capacity bus priority systems are the most practical solution to be implemented so far to solve the problem of high traffic demand and saturation. Rapid rail transit systems have proven to be uneconomical to establish and maintain. As a result of limited resources, creative and innovative low cost solutions to such transportation problems are more likely to be developed in third world countries than in developed ones. In developed countries, economic stability permits more sophisticated solutions such as high speed subway systems and the like to be implemented.

It has been observed that with the appropriate mix of operational and design features such as exclusive lanes, bus priority traffic signal, overtaking at stops and high capacity vehicles, bus systems have been able to achieve the same performance levels as rail transit but for far lower costs, having the additional advantages of route flexibility and demand adaptability.

Bus Rapid Transit (BRT) system is a new type and high efficient bus operator system, whose transportation capacity is close to the rail transportation, and has rapid construction speed, also can retrench the investigation. It mainly refers to ground bus automotive system with the features of dedicated road, closed operation, level boarding and a-lighting and large-capacity vehicles

Reducing the cost of operations is one of the most important considerations for urban transport systems' minimizing these costs is referred to as the bus-to-depot allocation problem and addressing it may be important in reducing overall costs. We present a model and an associated decision support system for optimally allocating buses to depots while minimizing costs and keeping depot occupancy at "ideal" operational levels

\section{Importance's Of Public Transportation System}

Public transportation provides people with mobility and access to employment, community resources, medical care, and recreational opportunities in communities across India. It benefits those who choose to ride, as well as those who have no other choice: over 90 percent of public assistance recipients do not own a car and 
must rely on public transportation. Public transit provides a basic mobility service to these persons and to all others without access to a car.

The incorporation of public transportation options and considerations into broader economic and land use planning can also help a community expand business opportunities, reduce sprawl, and create a sense of community through transit-oriented development. By creating a locus for public activities, such development contributes to a sense of community and can enhance neighborhood safety and security. For these reasons, areas with good public transit systems are economically thriving communities and offer location advantages to businesses and individuals choosing to work or live in them. And in times of emergency, public transportation is critical to safe and efficient evacuation, providing the resiliency American needs in its emergency transportation network.

Public transportation also helps to reduce road congestion and travel times, air pollution, and energy and oil consumption, all of which benefit both riders and non-riders

Expanding the availability of, safety for, and access to a variety of transportation options and integrating health-enhancing choices into transportation policy has the potential to save lives by preventing chronic diseases, reducing and preventing motor-vehicle-related injury and deaths, improving environmental health, while stimulating economic development, and ensuring access for all people.

With this goal in mind, the Centers for Disease Control and Prevention (CDC) has identified transportation policies that can have profound positive impact on health. CDC supports strategies that can provide a balanced portfolio of transportation choices that supports health and reduces health care costs. Transportation policy can:

- $\quad$ Reduce injuries associated with motor vehicle crashes

- Encourage healthy community design

- Promote safe and convenient opportunities for physical activity by supporting active transportation infrastructure

- $\quad$ Reduce human exposure to air pollution and adverse health impacts associated with these pollutants

- Ensure that all people have access to safe, healthy, convenient, and affordable transportation

\section{Comparison Of The Performance Of Various Investigations By Various Researchers}

Konstantinos Kepaptsoglou, in 2010 work on Reducing the cost of operations for urban transport systems Deadhead kilometer costs are an important aspect of operating costs and are associated with buses traveling empty to and from depots The model focused on both minimizing deadhead kilometres travelled by buses while preserving occupancy balance in depots Demand for transportation, coupled with high level-ofservice requirements in urban areas is frequently satisfied by extended bus networks that operate at high frequencies. Mohammed A. Quddus research on 2010 in level of traffic congestion and road safety One can expect that the increased level of traffic congestion aids road safety and this is because average traffic speed is relatively low in a congested condition relative to an uncongested condition which may result in less severe crashes. The relationship between congestion and safety may not be so straightforward; however, as there are a number of other factors such as traffic flow, driver characteristics, road geometry, and vehicle design affecting crash severity Two major factors in promoting economic productivity of a healthier economy are enhanced mobility and improved safety

Symeon E. Christodoulou in 2010 done a study on traffic flow estimation between known origins and destinations can be evaluated based on a modified entropy mode and by which bus-routing optimization can be performed The traffic flow analysis is performed by use of an entropy-based formulation of the vehicular movements of students within the domain under examination The entropy metric used in the scheduling optimization is related to the probability of student-trips by origin and destination Urban traffic modeling and planning is a highly complex problem, especially in urban domains with high volume of unplanned vehicular movements, such as in the case of urban locales with limited or no mass transit infrastructure. Urban transportation planning in such locales involves both the study of existing travel patterns. Marisa Garcia in 1994 compared the busways and bus lanes in Brazil and Japan on various parameter like characteristics of busways and bus lanes, physical characteristics of busways and bus lanes, operational characteristics and special features In Brazil, the expertise developed in establishing and operating busway and bus lane systems proved to be so successful that they could assist in setting up similar systems in other countries. In Japan, due to the narrowness of the streets, very few applications of such systems can be seen. The only examples of such systems in Japan are in Osaka and Nagoya City ( known for its large avenues, introduced as part of the war rehabilitation plan). Within Brazil, the most successful systems are in the southern cities of Sao Paulo, Curitiba, Porto Alegre and the central city of Belo Horizonte. The study also takes into account the differences in culture, environment, demand and physical characteristics between the two countries. 
Wanjing MA in 2007 develop a methodology for A Passive Transit Signal Priority Approach for Bus Rapid Transit System base on mathematically depicted the relationship between the departure frequency, cycle length of signalized intersection and number of Different Signal Status (DSS) when buses arrive at the intersection. The optimal number of DSS, which was found to be ONE, was obtained by analyzing their effects on the bus average delay and deviation of headway and also presented the following transit signal priority control strategies. For one DSS, a model to decide the optimal expected signal status when buses arrive at the intersection was proposed. 2). For two DSS, three signal priority strategies, green extension, phase rotation and phase splitting were proposed. Xue qingji in 2009 give recommendation on advantages of bus transit system over a rail transit system by using improvement entropy power law and quality synthetic evaluation method The analytic hierarchy process (AHP) is such a kind of method that always divides element levels about the policymaking into goals, criterion, plan and so on, carrying on qualitative and the quantitative analysis decision above this foundation. This method was American operation scientist troubles fort professor Suttees in the early-1970s, when studied for the United States Department of Defense acts according to each Industry sector carried on the electric power assignment topic to the national welfare's

Yin ZHU in 2010 was discus about bus signal priority for Bus Rapid Transit System is not only decreasing buses delay but also enhancing the reliability of bus service by keeping buses on schedule or maintaining bus headway adherence. One problem with existing bus priority strategies is that they do not care about the variances of sequential buses delay at intersections. Usually buses arrive at intersection at defined frequency and leave it at dramatically fluctuating headways because the signal statuses when each bus arrives at the intersection and delay for each bus are different. For BRT system, the travel time reliability of buses on links is improved dramatically, traffic signal control system may be the main sources to induce bus headway fluctuation and schedule deviation

\section{Concluding Remarks}

\begin{tabular}{|c|c|c|}
\hline $\begin{array}{l}\text { Name Of } \\
\text { Authors }\end{array}$ & $\begin{array}{l}\text { Title Of Paper And Year } \\
\text { Of Publications }\end{array}$ & Conclusion Of Authors \\
\hline Marisa Garcia & $\begin{array}{l}\text { BUSWAYS AND BUS } \\
\text { LANES IN BRAZIL AND } \\
\text { JAPAN In } 1994\end{array}$ & $\begin{array}{l}\text { The cooperation and discipline of private motor vehicle Drivers in } \\
\text { observing usage and parking restrictions. the reliability and effectiveness of } \\
\text { the bus operation In being able to convert private motor vehicle drivers Into } \\
\text { public transport users. }\end{array}$ \\
\hline Xue Qingji & $\begin{array}{l}\text { Evaluation On Sustainable } \\
\text { Development Of Rapid } \\
\text { Transit System Based On } \\
\text { The Improved Entropy } \\
\text { Method in } 2009\end{array}$ & $\begin{array}{l}\text { To use the entropy method to improve the comprehensive assessment, to a } \\
\text { large extent to reduce the weight of the human impact on the process when } \\
\text { determined by experts, so that the results of the evaluation to be able to } \\
\text { more accurately reflect the objective reality and the future development of } \\
\text { space, so as to provided the basis for municipal transportation's } \\
\text { development decision-making. }\end{array}$ \\
\hline Yin $\mathrm{ZHU}$ & $\begin{array}{l}\text { Study on Intelligent Traffic } \\
\text { Control Based BRT In } \\
2010\end{array}$ & $\begin{array}{l}\text { the average delay of the intersection will get longer than before since the } \\
\text { traffic control strategy is changed based on the BRT vehicle priority. } \\
\text { Especially when the traffic status gets saturated the conflict direction } \\
\text { vehicles will endure more delay at very big degree than other conditions. } \\
\text { when the BRT project is planned the signal control of the relative } \\
\text { intersections must be designed from all round aspects especially } \\
\text { considering the conflict direction traffic flow. }\end{array}$ \\
\hline Guojun Chen & $\begin{array}{c}\text { Bus-Arrival-Time } \\
\text { Prediction Models: Link- } \\
\text { Based and Section-Based in } \\
2012\end{array}$ & $\begin{array}{l}\text { Although several models have been developed that use AVL data in bus- } \\
\text { arrival-time prediction, some of them have to be recalibrated or even are } \\
\text { inapplicable in a new setting as key factors probably differ from one bus } \\
\text { route to another. Historical travel time-based models have the advantage of } \\
\text { generalization under various conditions, but at the cost of accuracy and } \\
\text { precision }\end{array}$ \\
\hline $\begin{array}{l}\text { Konstantinos } \\
\text { Kepaptsoglou }\end{array}$ & $\begin{array}{l}\text { Bus-to-Depot Allocation: } \\
\text { Models and Decision } \\
\text { Support System in } 2010\end{array}$ & $\begin{array}{l}\text { model for optimally allocating buses to depots in a large urban bus } \\
\text { network. The model focused on both minimizing deadhead kilometers } \\
\text { traveled by buses while preserving occupancy balance in depots }\end{array}$ \\
\hline $\begin{array}{l}\text { Mohammed A. } \\
\text { Quddus }\end{array}$ & $\begin{array}{l}\text { Road Traffic Congestion } \\
\text { and Crash Severity: } \\
\text { Econometric Analysis } \\
\text { Using Ordered Response } \\
\text { Models in } 2011\end{array}$ & $\begin{array}{l}\text { The factors that result in less severe crashes have been found to be traffic } \\
\text { flow, radius of road curvature, darkness light conditions, wet road surface } \\
\text { conditions, and time trend. The factors resulting in high severe crashes have } \\
\text { been found to be three-lane stretches of the motorway, single-vehicle crash, } \\
\text { and weekdays. } \\
\text { The gradient of road segment and time of the day were found to be } \\
\text { insignificant. One of the limitations of this study is that the traffic flow and } \\
\text { speed values were assigned to crashes based on segment measurements. } \\
\text { However, segments would not necessarily have uniform conditions over } \\
10-\mathrm{km} \text { length if queues are present. }\end{array}$ \\
\hline
\end{tabular}




\section{Recommendations}

Transportation system has been shaped by multiple policy inputs and concrete actions which have arisen from transportation and community planners, funding agencies and others at Federal, state and local levels. Today, the system is designed to move people and goods efficiently; however, there is a growing awareness across communities that transportation systems impact quality of life and health. Government and non-government agencies are seeking innovative policies and programs that protect and promote health while accomplishing the primary transportation objectives

\section{References}

[1]. Konstantinos Kepaptsoglou," Bus-to-Depot Allocation: Models and Decision Support System" JOURNAL OF "TRANSPORTATION ENGINEERING" of ASCE vol 10 P.P. 600-605 (2010)

[2]. Guojun Chen "Bus-Arrival-Time Prediction Models: Link-Based and Section-Based" JOURNAL OF "TRANSPORTATION ENGINEERING" of ASCE vol 12 P.P. 60-65 (2012)

[3]. Hongfeng Xu, "Impact of Bus-Only Lane Location on the Developmentand Performance of the Logic Rule-Based Bus Rapid Transit Signal Priority " JOURNAL OF “TRANSPORTATION ENGINEERING” of ASCE P.P. 293-314 (2012)

[4]. Mohammed A. Quddus, "Road Traffic Congestion and Crash Severity: Econometric Analysis Using Ordered Response Models" JOURNAL OF "TRANSPORTATION ENGINEERING" of ASCE P.P. 424-435 (2010)

[5]. Yin ZHU "Study on Intelligent Traffic Control Based BRT" journal of IEEE P.P. 11-14 (2010)

[6]. Xue qingji "Evaluation On Sustainable Development Of Rapid Transit System Based On The Improved Entropy Method" JOURNAL OF “TRANSPORTATION ENGINEERING” of ASCE vol 1 P.P. 196-200 (2009)

[7]. Marisa Garcia "BUSWAYS AND BUS LANES IN BRAZIL AND JAPAN" JOURNAL OF "TRANSPORTATION ENGINEERING” of ASCE vol 6 P.P. 689-694 (1994) 